\title{
Eighteen-month clinical performance of composite resin restorations with two different adhesive systems for molars affected by molar incisor hypomineralization
}

\author{
Juliana Feltrin de Souza ${ }^{1}$ - Camila Bullio Fragelli ${ }^{2}$ - Fabiano Jeremias ${ }^{2}$. \\ Marco Aurélio Benini Paschoal ${ }^{3}$ - Lourdes Santos-Pinto ${ }^{2}$. \\ Rita de Cássia Loiola Cordeiro ${ }^{2}$
}

Received: 1 October 2015 / Accepted: 4 October 2016 / Published online: 15 October 2016

(C) Springer-Verlag Berlin Heidelberg 2016

\begin{abstract}
Introduction The restorative management of molars with molar incisor hypomineralization (MIH) represents a challenge in the clinical practice with high failure rate.

Objective The aim of this study is to evaluate the clinical survival of direct composite resin restorations in first permanent molars (FPMs) that are affected by MIH, comparing two adhesive systems.

Material and methods We selected 41 FPMs with MIH from children aged 6-8 years. FPM fully erupted and with restorative treatment needed were the inclusion criteria. We excluded FPMs with destroyed crowns. The FPMs were randomly assigned to two groups: self-etching adhesive (SEA) and totaletch adhesive (TEA). Clinical evaluation was performed by a blinded examiner during 18 months according to the modified US Public Health Service (USPHS) criteria. The actuarial method was used to evaluate survival of the restorations, and Chi-square and Fisher's exact tests were used to compare differences between the groups ( $\alpha=5 \%)$.

Results The cumulative survival rates were $100 \%$ at 1 month, $89 \%$ at 6 months, $73 \%$ at 12 months, and $68 \%$ at 18 months in SEA, and $95 \%$ at 1 month, $72 \%$ at 6 months, $59 \%$ at
\end{abstract}

Juliana Feltrin de Souza

julianafeltrin@hotmail.com

1 Department of Stomatology, School of Dentistry, Federal University of Paraná, UFPR, Paraná, Brazil

2 Department of Pediatric Dentistry and Orthodontic, Araraquara School of Dentistry, UNESP - Univ Estadual Paulista, São Paulo, Brazil

3 Master's Program in Dentistry, CEUMA University, São Luis, Maranhão, Brazil
12 months, and $54 \%$ at 18 months in TEA; there was no significant difference between groups.

Conclusions There was no difference in clinical survival of restorations in FPMs affected by MIH using TEA or SEA adhesives in the end of 18 months.

Clinical relevance It was suggested that SEAs as well as TEAs can be applied to restore molars affected by MIH, when it is performed a conservative cavity preparation. Once, cavosurface margins (cavity design) in hypomineralized enamel have less bonding capability.

Keywords Molar incisor hypomineralization · Randomized clinical trial · Treatment · Dental restoration · Adhesive system

\section{Introduction}

In addition to caries decay, pediatric dentists are currently confronted by a high prevalence of enamel defects in first permanent molars (FPMs), called molar incisor hypomineralization (MIH), during or soon after eruption [1]. Which is challenging, defined as a developmentally derived dental defect that involves hypomineralization of the first to fourth FPMs. It is frequently associated with permanent incisors [2]. This condition is presumed to result from various environmental factors that act systemically to affect the developing enamel, beginning prenatally and persisting into childhood [3-6]. This condition is also possibly associated with genetic polymorphisms [7].

Clinically, teeth affected by MIH present wide variations in severity [8]. The mild form of MIH is associated with isolated demarcated opacities that vary from white to brown in nonstress-bearing areas of the FPMs, with no loss from fracturing [8-11]. Moderate and severe MIH is frequently associated with atypical restorations and demarcated opacities in the 
occlusal/incisor third of teeth that occasionally undergoes posteruptive breakdown because of the soft and porous enamel. Widespread caries are often associated with the affected enamel $[12,13]$. In MIH, hypomineralization lesions can occur independently or coexist with hypoplastic lesions in one or more teeth, depending on the time, duration, and susceptibility of the individual and severity of the prenatal, perinatal, or postnatal insult [13]. MIH is frequently present in Brazilian children, with a prevalence of $12.3-40.2 \%$, posing a considerable clinical problem for this population [10, 12, 14-16].

MIH presents a serious clinical management challenge that has attracted the attention of the dental profession $[8,11,12$, 17-20]. These enamel defects negatively affect the quality of children's life. They frequently report shooting pains while eating ice cream or even while breathing cold air. This intrinsic sensitivity can influence the children's behavior. They are commonly reluctant to open their mouth and negatively react to blowing air. Furthermore, treatment can be painful because of difficulties achieving local analgesia, which is attributable to subclinical inflammation of the pulp because of the porosity of the enamel [21].

Enamel that is affected by MIH exhibits disorganized enamel prisms, a porous structure, low mineral content, and loosely packed crystallites [22-25], which are correlated with lower strength and hardness of the enamel $[22,26]$. These features can explain the risk of rapid caries development and restoration failures. Molars that are affected by MIH undergo dental treatment nearly ten times more often compared with molars without MIH [21].

Many dental restorative materials are available. In teeth with severe $\mathrm{MIH}$, stainless steel crowns are the treatment of choice $[13,27]$. Amalgam is a nonadhesive material that is not indicated to atypical cavities. Its use can result in further enamel breakdown $[13,28]$. Other possible treatment modalities include polyacid-modified composite resins, composite resins, indirect alloys, glass-ionomer cement (GIC), resinmodified GIC, and fissure sealants [13]. Glass-ionomer cement is an important tool for combating caries. This type of cement is thought of as a reservoir of fluoride and other ions in the oral cavity and mechanical barrier that protects the tooth surface against bacteria. Its most important property is that it can provide a long-lasting seal under the most challenging clinical circumstances [11, 28]. Glass-ionomer cement should be used as an intermediate approach until a definitive restoration is placed [11, 13, 24], such as an intermediate layer protecting dentinal contours prior to composite placement [28], or it can serve as a definitive restorative material [11].

Adhesive bonding to hypomineralized enamel may also be used. Various types of adhesive systems are available [29, 30]. Self-etching has been suggested to enhance the adhesion strength of resin composites in hypomineralized enamel [27]. However, because of a mineral deficiency of hypomineralized teeth, adhesives have a lower ability to adhere to the tooth surface [25]. The literature, especially in vivo studies, shows that adhesion to hypomineralized enamel is limited. Some authors recommend pretreating the enamel with $5 \%$ sodium hypochlorite, and others suggest removing defective hypomineralized enamel prior to bonding resin composite restorations. However, few clinical studies have longitudinally evaluated this procedure $[17,28]$. Thus, the aim of the present study was to evaluate the clinical survival of direct composite resin restorations in FPMs that are affected by MIH, comparing two adhesive systems.

\section{Materials and methods}

\section{Study design}

This study was conducted in full accordance with ethical principles, including the World Medical Association Declaration of Helsinki (2008). It was also approved by the Ethics and Research Committee at Araraquara Dental School (FOArUNESP), São Paulo, Brazil (protocol no. 11/08). The parents or guardians of the children provided written, free, and informed consent for this randomized, blinding clinical trial. It has evaluated 1147 children 6 to 8 years of age. Of these, 142 presented MIH (Fig. 1) and 26 presented FPMs that required restorative treatment. Of these 26 children, 18 met the inclusion criteria of the study. The present study is registered at ClinicalTrials.gov (NCT02717286).

The inclusion criteria were children who were born and living in Araraquara, SP, Brazil, who presented totally erupted FPMs with MIH classified as enamel posteruptive breakdown (PEB) or unsatisfactory atypical restoration (UATR), with or without carious lesions. The exclusion criteria were tooth enamel malformation associated with syndromes, dental fluorosis, FPMs with destroyed crowns, imperfect amelogenesis, and fixed orthodontic appliances.

After selection of subjects, a total of 41 FPMs with MIH were included and were treated based on a clinical protocol, in which they were provisionally restored, permanently restored, monitored every 6 months for 18 months, and evaluated in terms of modified US Public Health Service (USPHS) criteria to determine the rates of success.

All teeth were treated with direct composite resin restorations, which were randomized into two groups according to the adhesive system that was applied: self-etching adhesive (SEA) and total-etch adhesive (TEA) that was considered the standard procedure (control group) and restored with composite resin [27]. To balance the sample size between the groups, the randomization method adopted was a blocked randomization, which is a fixed allocation randomization method. For this method, it was defined as a block of four teeth, in each a simple randomization tossing an unbiased coin for the first three teeth, and the last one was allocated in the group with minor sample. 


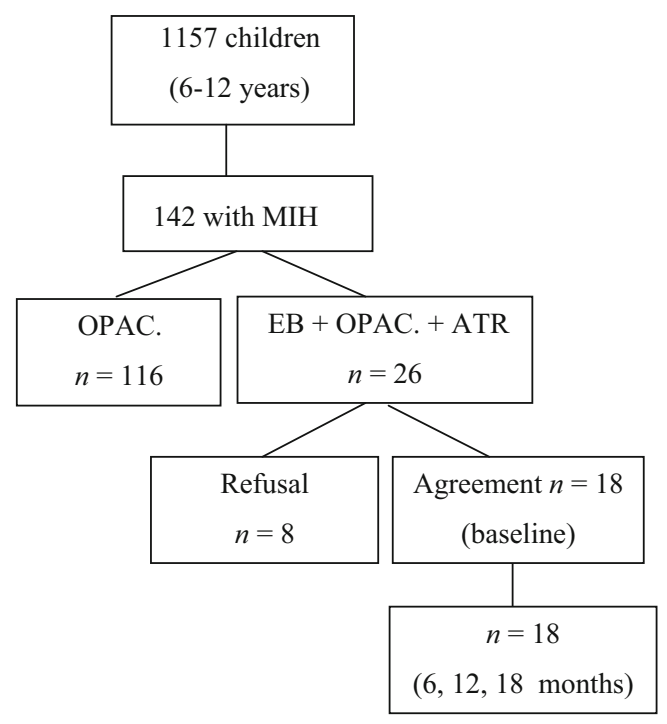

Fig. 1 Number of subjects of the study. OPAC opacities, $E B$ enamel breakdown, ATR atypical restoration

\section{Restorative treatment protocol}

A calibrated pediatric dentist examined the selected teeth to classify MIH according to the EAPD criteria [31], carious lesions according to the decay-missing-filled teeth (DMFT) index [32], and restoration integrity according to the restoration quality criteria proposed by the USPHS-modified criteria [33].

The calibration process was taken previously in different moment for the criteria used (MIH, DMFT index, and USPHS-modified), involving the theoretical training and practice using photography of the criteria situations. Then, the practice of calibration was performed with patients in the clinical. The pediatric dentist examined others 20 patients, who were in attendance in the clinical practice, according the three criteria twice with 2 weeks of interval. The kappa coefficient of intraexaminer reliabilities were above 0.80 , which were 0.88 for MIH, 0.91 for DMT index, and 0.81 for the USPHS-modified criteria.

Bitewing radiographies were used to check the presence of caries lesion on MIH-affected areas and to establish the restorative procedures.

Another operator, with 10 years of clinical experience, performed the tooth restorations according to the following protocol: (1) 1 month of fluoride varnish application (Duraphat, Colgate, New York, NY, USA) using an applicator (Microbrush Int., Grafton, WI, USA) with cotton roll isolation, at an interval of 1 week and (2) provisional restoration with GIC according to the clinical protocol (infiltrative anesthesia, rubber dam, caries removal with low speed, $1 \%$ chlorhexidine application, protection of the dentin-pulp complex with calcium hydroxide if necessary, temporary restoration with Ketac Molar Easymix (3M ESPE, St. Paul, MN, USA) according to the manufacturer's instructions, removal of the rubber dam, checking the occlusion with a blue paper record, and surface protection with insulating). Finally, photographs and radiographs were taken and dietary and hygiene instructions were given.

After 2 months, the teeth were randomly divided into two groups that received the definitive Filtek XT350 restoration (3M ESPE, St. Paul, MN, USA) varying the adhesive: SEA (Clearfil SE Bond, Kuraray Medical, Tokyo, Japan) and TEA (Adper Scotchbond Multi-Purpose, 3M ESPE, St. Paul, MN, USA). Materials, respective lot numbers, composition, and manufacturer's instructions for use are provided in Table 1.

The SEA teeth $(n=19)$ were restored according to the following operative sequence: prophylaxis, infiltrative anesthesia, rubber dam, partial removal of GIC, primer application using an applicator $(20 \mathrm{~s})$, air jet $(5 \mathrm{~s})$ from $10-\mathrm{cm}$ distance with $45^{\circ}$ angle of the tip, adhesive application ( $5 \mathrm{~s}$ ) using an applicator, and light curing (10 s) with a light-curing unit (Elipar FreeLight 2, 3M ESPE). The intensity of the light exceeded $500 \mathrm{~mW} / \mathrm{cm}^{2}$. After application of the dentin adhesive using an applicator, Filtek Z350 XT (3M ESPE, St. Paul, MN, USA) was inserted in increments of 1.0-1.5 mm, and each increment was polymerized for $40 \mathrm{~s}$, followed by removal of rubber dam, examination of occlusal contact, and final polishing.

The TEA teeth $(n=22)$ underwent the following clinical steps: prophylaxis, infiltrative anesthesia, rubber dam, partial removal of GIC, application of $37.5 \%$ phosphoric acid to enamel (30 s) and dentine (15 s), extensive washing, drying with cotton and air jet $(5 \mathrm{~s})$ from $10-\mathrm{cm}$ distance with $45^{\circ}$ angle of the tip, priming ( $5 \mathrm{~s}$ ) using a applicator, air jet $(5 \mathrm{~s})$ from $10-\mathrm{cm}$ distance with $45^{\circ}$ angle of the tip, adhesive application (5 s) using an applicator, light curing (20 s), restoration with Filtek Z350 XT inserted in increments of 1.0-1.5 mm, where each increment was polymerized for $40 \mathrm{~s}$, removal of rubber dam, examination of occlusal contact, and final polishing.

\section{Follow-up and clinical evaluation}

Five clinical exams (baseline and at 1, 6, 12, and 18 months) were performed in a clinical environment according to a World Health Organization protocol [32] under artificial light and after prophylaxis. All of the children were followed up at 6-month intervals for a preventive program that included dietary and oral hygiene instructions, teeth cleaning, and fluoride gel application (5 \% NaF, neutral pH, FGM, Joinville, SC, Brazil) if indicated.

The restorations were clinically evaluated by a blinded and calibrated examiner (kappa 0.81) according to restoration quality criteria proposed by the USPHS-modified criteria [33], which consider anatomical form, marginal adaptation, surface texture, marginal discoloration, retention, and the presence of secondary carious lesions. The restorations were also classified as satisfactory or unsatisfactory (Table 2); when 
Table 1 Composition of materials used in the present study

\begin{tabular}{|c|c|c|c|}
\hline Product name & $\begin{array}{l}\text { Manufacturer } \\
\text { Lot number }\end{array}$ & Composition & Usage instruction \\
\hline Ketac Molar Easymix & $\begin{array}{l}\text { 3M ESPE, St Paul, MN, USA } \\
\text { Lot no. } 451964\end{array}$ & $\begin{array}{l}\text { Powder: aluminum-calcium-lanthanum, } \\
\text { fluorosilicate glass, } 5 \% \text { copolymer } \\
\text { acid (acrylic and maleic acids) } \\
\text { Liquid: polyalkenoic acid, tartaric acid, water }\end{array}$ & $\begin{array}{l}\text { Manual mixed, a mixing ratio (weight ratio) } \\
\text { of } 4.5 \text { parts of powder ( } 1 \text { spoonful with } \\
\text { leveled powder surface) } 1 \text { part of liquid } \\
\text { ( } 1 \text { drop). }\end{array}$ \\
\hline Filtek XT350 & $\begin{array}{l}\text { 3M ESPE, St Paul, MN, USA } \\
\text { Lot no. } 182351 \\
\text { Lot no. } 182963\end{array}$ & $\begin{array}{l}\text { Organic phase: UDMA, Bis-EMA, Bis- } \\
\text { GMA, TEGDMA } \\
\text { Inorganic matrix: silica ( } 20 \mathrm{~nm} \text { non-agglomerated/ } \\
\text { aggregated), zirconia (4-11 nm non- } \\
\text { agglomerated/aggregated and TEGDMA } \\
\text { agglomerated), clusters, zirconia/ silica } \\
\text { aggregated particles ( } 20 \mathrm{~nm} \text { silica particles } \\
\text { combined with 4-11 nm zirconia } 3 \text { ) }\end{array}$ & $\begin{array}{l}\text { Insertion in increments of } 1.0-1.5 \mathrm{~mm} \text {. } \\
\text { Each increment was polymerized for } 40 \mathrm{~s}\end{array}$ \\
\hline Clearfil SE Bond & $\begin{array}{l}\text { Kuraray Medical Inc., } \\
\text { Okoyama, Japan } \\
\text { Lot no. } 5 \mathrm{AB}\end{array}$ & $\begin{array}{l}\text { Primer: water, MDP, HEMA, CQ, DET, } \\
\text { hydrophilic DMA } \\
\text { Bond: MDP (bis-GMA, HEMA), CQ, DET, } \\
\text { hydrophilic DMA, silanted colloidal silica }\end{array}$ & $\begin{array}{l}\text { Apply the primer and leave for } 20 \mathrm{~s} \text {. Do } \\
\text { not rinse. Dry with mild airflow. Apply } \\
\text { bond and distribute evenly with mild air } \\
\text { flow. Light cure for } 10 \mathrm{~s}\end{array}$ \\
\hline $\begin{array}{l}\text { Adper Scotchbond } \\
\text { Multi-Purpose }\end{array}$ & $\begin{array}{l}\text { 3M ESPE, St Paul, MN, USA } \\
\text { Etchant: lot } 8 \mathrm{MP} \\
\text { Primer: lotno. 9CC } \\
\text { Adhesive: lot no. 9RL }\end{array}$ & $\begin{array}{l}\text { Etchant: 3M ESPE-35 \% phosphoric acid } \\
\text { Primer: water (40-50 wt } \%) \text {, HEMA } \\
\quad(35-45 \mathrm{wt} \%) \text {, copolymer of acrylic } \\
\text { and itaconic acids (10-20 wt } \%) \\
\text { Adhesive: Bis-GMA ( } 60-70 \mathrm{wt} \%) \\
\text { HEMA (30-40 wt } \%) \text {. }\end{array}$ & $\begin{array}{l}\text { Apply Scotchbond etchant to enamel and } \\
\text { dentin. Wait } 15 \mathrm{~s} \text {. Rinse for } 15 \mathrm{~s} \text {. } \\
\text { Dry for } 5 \mathrm{~s} \text {. } \\
\text { Apply Adper Scotchbond multi-purpose } \\
\text { primer to etched enamel and dentin. Dry } \\
\text { gently for } 5 \mathrm{~s} \text {. Apply Adper Scotchbond } \\
\text { multi-purpose adhesive to primed enamel } \\
\text { and dentin. Light-cure for } 10 \mathrm{~s} \text {. }\end{array}$ \\
\hline
\end{tabular}

Sources of the compositions (3M ESPE Technical product profile Filtek, p. 2 on http://www.3mespe.com; 3M ESPE Technical product profile Adper p. 2 on http://solutions.3mae.ae/.../Multi-Purpose-Dental-Adhesive/\#tab5; 3M ESPE Technical product profile Ketac Molar Easymix, p. 3 on http://www.3 mespe.com; Kuraray Safety datasheet article \# US064-B. p. 1 on www.kuraraydental.com)

Bis-GMA bisphenol A-glycidyl methacrylate, UDMA urethane dimethacrylate, TEGDMA triethylene glycol dimethacrylate, Bis-EMA bisphenol A ethoxylate dimethacrylate, HEMA 2-hydroxyethyl methacrylate, $M D P$ 10-methacryloxydecyldihydrogen phosphate, $D E T N, N$-diethanol-p-toluidine, $D M A$ dimethacrylate, $C Q$ camphorquinone

it was any of the Charlie ratings in the USPHS-modified criteria, the restoration was deemed unsatisfactory. An unsatisfactory condition was considered a failure, which was permanently eliminated from further consideration in the study. It was replaced, and a new restoration was performed, which was a clinical follow-up; however, it was not included in the study.

This clinical trial was blinded once, and neither the participant nor the examiner (investigators responsible for following the restorations and assessing outcomes) knew the identification of the groups.

\section{Statistical analysis}

The data were analyzed using the SPSS 16.0 software (SPSS, Chicago, IL, USA). Descriptive statistics were used to present the results. The actuarial method was used to evaluate survival of the restorations. Significant differences in survival rates between groups were analyzed using the log-rank MantelCox test. Comparisons between groups were performed using Fisher's exact test at a level of significance of $5 \%$.

\section{Results}

The mean participant age was 7 years old (range, 6-8 years), and $55 \%$ was female. Table 3 presents the frequencies of failure during follow-up and survival rates. The frequency of failure during the 18-month follow-up was 6 in SEA and 10 in TEA. The rates of restoration success at the end of the 18month follow-up were $68 \%$ for SEA and $54 \%$ for TEA, which were not significantly different $(p=0.304)$ (Table 3 , Fig. 2) .

A total of 16 teeth presented restoration failure in the Table 4. In the SEA group, the failure rate was significantly higher in the upper teeth than that in lower ones $(p=0.019)$. However, in the TEA group, there is no significant difference in the failure rates between upper and lower teeth $(p=0.305)$. Five of the 16 teeth had caries associated with restoration failure ( 3 in SEA and 2 in TEA; Table 5). No significant differences in any of the evaluation criteria were found among the evaluation categories (Table 5). 
Table 2 US Public Health Service (USPHS)-modified criteria for classifying restorations as satisfactory and unsatisfactory

\begin{tabular}{lll}
\hline Criterion & Score & Clinical situation \\
\hline Anatomical form & Alfa & Continuous \\
& Bravo & Slight discontinuity, clinically acceptable \\
Charlie & Discontinuous, failure \\
Marginal adaptation & Alfa & Closely adapted, no visible crevice \\
& Bravo & Visible crevice, explorer will penetrate \\
Charface texture & Alfa & Crevice in which dentin is exposed \\
& Bravo & Enamel-like surface \\
Marginal discoloration & Charlie & Surface rougher than enamel, clinically acceptable \\
& Alfa & Surface unacceptably rough \\
& Bravo & No discoloration \\
Retention & Charlie & Discoloration without penetration in pulpal direction \\
& Alfa & Discoloration with penetration in pulpal direction \\
Secondary caries & Charlie & No loss of restorative material \\
& Alfa & Any loss of restorative material \\
& Charlie & Caries present \\
\hline
\end{tabular}

\section{Discussion}

One problem of the present experiment was concerning of the challenges regarding to the treatment of molars affected by $\mathrm{MIH}$, including efficient anesthesia, suitable cavity design, and the choice of material. Once, hypomineralized enamel has deficient mechanical proprieties, including strength and hardness, which can cause restoration failure. Restorative treatment success usually depends on the severity of the MIH lesions, hygiene habits, the child's cooperation, and age. In the present study, the sample was selected based on strict inclusion and exclusion criteria. Thus, the sample was composed of severe cases of MIH with posteruptive enamel breakdown, caries lesions, and opacities associated with atypical restorations. However, a limitation of the present study was the number of sample that could be higher. Another problem of the restorative management of molars affected by MIH which should be taken in consideration is as follows: how much affected enamel has to be removed, suitable materials, and the best option for the adhesive system (when necessary). This appears to be the first randomized clinical trial that evaluated longitudinally the survival of restorations in molars that were affected by MIH using two adhesive systems.

A good clinical target success is not evidenced for composite restorations in hypomineralized molars; this would be around $60 \%$ at 18 months, considering the multiple surfaces involved and a conservative cavity margin design. Recent clinical trial found a survival rate of $57.9 \%$ for adhesive restorations on young permanent teeth, without hypomineralization, up to 36 months of follow-up. The authors concluded that adhesive restorations performed in young permanent molars of high caries risk children presented limited survival [34]. In this study, the survival rates were around 68 and $54 \%$ for self-etching and total-etch, respectively, which clinically means that $68 \%$ of the restoration with self-etching adhesive and $54 \%$ of the restoration with total-etch adhesive were satisfactory in the end of 18 months. It is considered a good clinical survival for hypomineralized young permanent teeth, once known that

Table 3 Actuarial method survival analysis for both groups

\begin{tabular}{lllllll}
\hline & Interval (months) & $\begin{array}{l}\text { Subjects living at } \\
\text { start of interval }\end{array}$ & $\begin{array}{l}\text { Failure during } \\
\text { the interval }\end{array}$ & $\begin{array}{l}\text { Failure rate during } \\
\text { the interval }\end{array}$ & $\begin{array}{l}\text { Survival rate during } \\
\text { the interval }\end{array}$ & $\begin{array}{l}\text { Cumulative survival rate } \\
\text { to end of interval }\end{array}$ \\
\hline SEA & $(0-1)$ & 19 & 0 & 0.000 & 1.000 & 1.000 \\
& $(1-6)$ & 19 & 2 & 0.105 & 0.895 & 0.895 \\
& $(6-12)$ & 17 & 3 & 0.176 & 0.824 & 0.737 \\
& $(12-18)$ & 14 & 1 & 0.071 & 0.929 & 0.684 \\
TEA & $(0-1)$ & 22 & 1 & 0.045 & 0.955 & 0.955 \\
& $(1-6)$ & 21 & 5 & 0.238 & 0.762 & 0.727 \\
& $(6-12)$ & 16 & 3 & 0.187 & 0.813 & 0.591 \\
& $(12-18)$ & 13 & 1 & 0.076 & 0.924 & 0.546 \\
\hline
\end{tabular}

Differences between groups were analyzed by the log-rank Mantel-Cox test $(p=0.304)$ 
Fig. 2 Restoration survival over time (Kaplan-Meier test), where censored data was attributed to restoration satisfactory on the 18th month

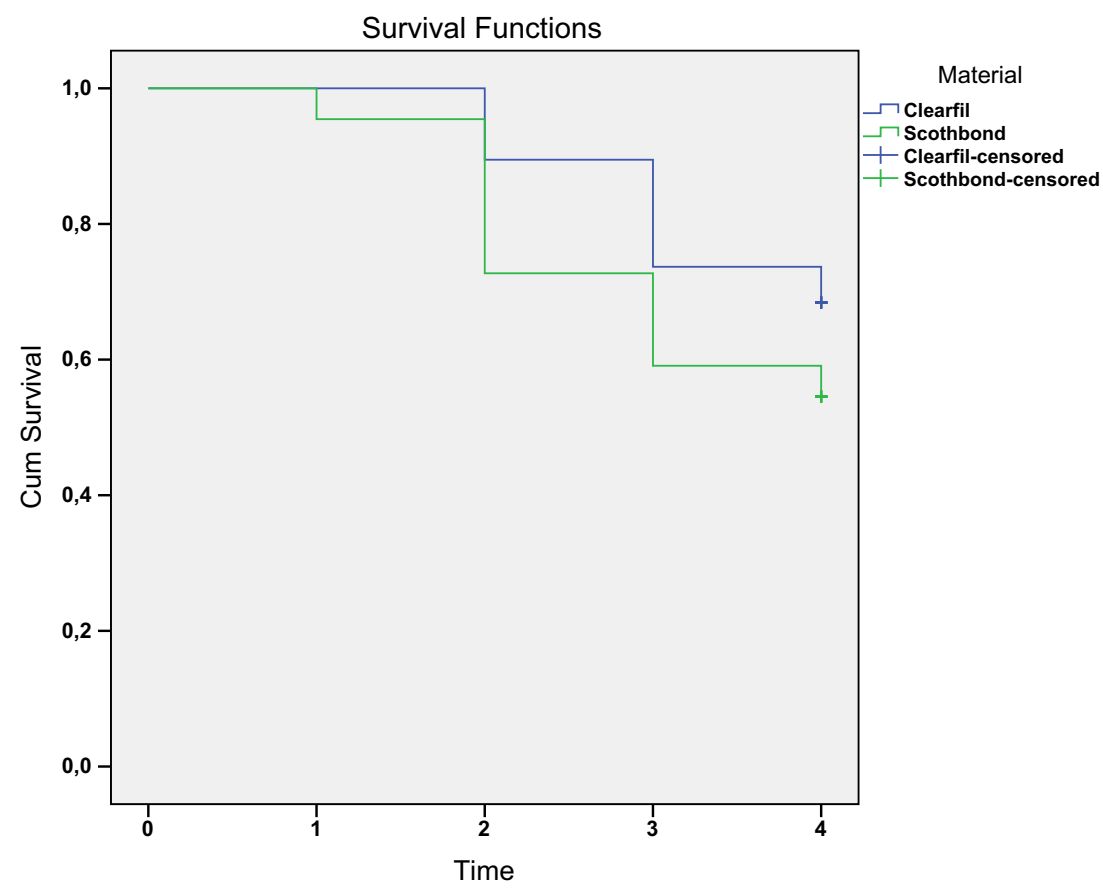

molars affected by $\mathrm{MIH}$ have more retreatments. Jalevik et al. [21] in a retrospective study in Sweden compared 32 children with MIH and 41 control children with regard to FPM restoration. At age 9, the children with MIH had undergone FPM treatment nearly ten times more often than the control children. On average, each affected molar had been treated twice due to restoration failure, posteruptive breakdown, or recurrence of caries. However, the control group had no retreated FPMs [21].

Regarding the reasons that could explain the failure rates presented is the conservative cavity margin design. An important aspect in restoring molars affected by $\mathrm{MIH}$ with composite resin is related to the cavosurface margins, which can be difficult to place because of the surface's uncertain bonding capability [27]. This aspect can be in part one of the causes of failure. Two approaches have been proposed: removal of all defective enamel until reaching a sound surface $[18,28]$ and removing the porous

Table 4 Association between unsatisfactory restorations according to type of tooth in both groups after 18 months

\begin{tabular}{|c|c|c|c|c|c|c|c|}
\hline \multirow[t]{2}{*}{ Material } & & \multicolumn{4}{|c|}{ Tooth } & \multirow[t]{2}{*}{ Total } & \multirow[t]{2}{*}{$p$ value } \\
\hline & & $\begin{array}{l}16 \\
n\end{array}$ & $\begin{array}{l}26 \\
n\end{array}$ & $\begin{array}{l}36 \\
n\end{array}$ & $\begin{array}{l}46 \\
n\end{array}$ & & \\
\hline \multirow[t]{3}{*}{ SEA } & Success & 1 & 2 & 5 & 5 & 13 & \multirow[t]{3}{*}{0.019} \\
\hline & Failure & 3 & 3 & 0 & 0 & 6 & \\
\hline & Total & 4 & 5 & 5 & 5 & 19 & \\
\hline \multirow[t]{3}{*}{ TEA } & Success & 2 & 7 & 1 & 2 & 13 & \multirow[t]{3}{*}{0.305} \\
\hline & Failure & 4 & 2 & 2 & 2 & 10 & \\
\hline & Total & 6 & 9 & 3 & 4 & 22 & \\
\hline
\end{tabular}

The results were analyzed using Chi-square test and Fisher's exact test enamel only until the bur or the probe meets resistance [17]. According to Lygidakis [13], the first approach involves lost of tooth structure, but it is better if an adhesive material relies upon bonding to sound enamel. The second one is a more conservative approach; however, the defective enamel may continue to chip away. However, the literature recommends the removal of all hypomineralized enamel prior to place composite resin [28]. It was contended that the choice of the proper cavity design depends on the extent of the enamel defect in the crown, the presence of carious lesions, the age of the child, and the stage of eruption in the mouth. Thus, the conservative approach is indicated in some cases. Fragelli et al. [8] showed that the hypomineralized enamel can be maintained intact with preventive treatment. However, it was observed in vitro that bond strengths of composite resin to hypomineralized enamel of PFMs affected with $\mathrm{MIH}$ are significantly less than bond strengths to normal enamel for both total etch and self-etching adhesives [27, 28].

Comparing the survival rates with previous study, Lygidakis et al. [17] evaluated the clinical performance of 52 composite restorations in FPMs using total-etch of one-bottle adhesive. They performed a follow-up of 49 restorations and observed full retention in all of the restorations over 48 months. The clinical evaluation could notice considerable differences in the color match (9 from 49 teeth). Clinical success of $100 \%$ may be related to the removal of all clinically defective soft enamel that allowed the composite resin to adhere to the remaining, possibly normal enamel. Other studies showed that composite resin material has much longer-term stability compared with other restorative materials in $\mathrm{MIH}$ teeth, with a median survival rate of 5.2 years $[13,19]$ and a success rate of 74-100\% [13, $17,20]$ during a 4-year follow-up period. In the present study, 
Table 5 Satisfactory and unsatisfactory restorations for the groups at the five clinical exams

\begin{tabular}{|c|c|c|c|c|c|c|c|c|c|}
\hline \multirow[b]{2}{*}{ Criterion } & & \multicolumn{2}{|c|}{1 month } & \multicolumn{2}{|c|}{6 months } & \multicolumn{2}{|c|}{12 months } & \multicolumn{2}{|c|}{18 months } \\
\hline & & SEA & TEA & SEA & TEA & SEA & TEA & SEA & TEA \\
\hline \multirow[t]{3}{*}{ Anatomic form } & Satisfactory & 19 & 22 & 19 & 21 & 17 & 16 & 13 & 12 \\
\hline & Unsatisfactory & 0 & 0 & 0 & 0 & 0 & 0 & 1 & 0 \\
\hline & & \multicolumn{2}{|c|}{$p=1.000$} & \multicolumn{2}{|c|}{$p=1.000$} & \multicolumn{2}{|c|}{$p=1.000$} & \multicolumn{2}{|c|}{$p=1.000$} \\
\hline \multirow[t]{3}{*}{ Marginal adaptation } & Satisfactory & 19 & 21 & 17 & 19 & 16 & 14 & 13 & 12 \\
\hline & Unsatisfactory & 0 & 1 & 2 & 2 & 1 & 2 & 1 & 0 \\
\hline & & \multicolumn{2}{|c|}{$p=1.000$} & \multicolumn{2}{|c|}{$p=1.000$} & \multicolumn{2}{|c|}{$p=0.601$} & \multicolumn{2}{|c|}{$p=1.000$} \\
\hline \multirow[t]{3}{*}{ Surface texture } & Satisfactory & 19 & 21 & 18 & 19 & 17 & 14 & 14 & 12 \\
\hline & Unsatisfactory & 0 & 1 & 1 & 2 & 0 & 2 & 0 & 0 \\
\hline & & \multicolumn{2}{|c|}{$p=1.000$} & \multicolumn{2}{|c|}{$p=1.000$} & \multicolumn{2}{|c|}{$p=0.227$} & \multicolumn{2}{|c|}{$p=1.000$} \\
\hline \multirow[t]{3}{*}{ Marginal discoloration } & Satisfactory & 19 & 22 & 19 & 19 & 16 & 14 & 14 & 12 \\
\hline & Unsatisfactory & 0 & 0 & 0 & 2 & 1 & 2 & 0 & 0 \\
\hline & & \multicolumn{2}{|c|}{$p=1.000$} & \multicolumn{2}{|c|}{$p=0.488$} & \multicolumn{2}{|c|}{$p=0.601$} & \multicolumn{2}{|c|}{$p=1.000$} \\
\hline \multirow[t]{3}{*}{ Retention } & Satisfactory & 19 & 20 & 17 & 16 & 14 & 14 & 13 & 12 \\
\hline & Unsatisfactory & 0 & 2 & 2 & 5 & 3 & 2 & 1 & 1 \\
\hline & & \multicolumn{2}{|c|}{$p=0.490$} & \multicolumn{2}{|c|}{$p=0.412$} & \multicolumn{2}{|c|}{$p=1.000$} & \multicolumn{2}{|c|}{$p=1.000$} \\
\hline \multirow[t]{3}{*}{ Secondary caries } & Satisfactory & 19 & 22 & 18 & 20 & 16 & 15 & 13 & 13 \\
\hline & Unsatisfactory & 0 & 0 & 1 & 1 & 1 & 1 & 1 & 0 \\
\hline & & \multicolumn{2}{|c|}{$p=1.000$} & \multicolumn{2}{|c|}{$p=1.000$} & \multicolumn{2}{|c|}{$p=1.000$} & $p=1$ & \\
\hline
\end{tabular}

The results were analyzed using Fisher's exact test the survival rate of the restorations was lower than these reports, likely because of the remaining hypomineralized enamel defects. Thus, the composite resin should be used clinically in molars affected by MIH; comparing the literature with our data, the clinical survival of composite restorations was higher when the cavity margins are on sound enamel.

With regard to restorative materials, very little evidence is available to support the use of one approach over another for FPMs that are affected by MIH [13]. However, GIC is not recommended in stress-bearing areas [24, 28]. Fragelli et al. [11] evaluated the clinical performance of GIC restorations in molars that were affected by $\mathrm{MIH}$ and found high survival rates (91.7\% after 6 months and $78.7 \%$ after 12 months). These results are similar to the present results for the self-etching primer and higher than the survival rates for the total-etch adhesive. These results can be explained by the fact that GIC has a coefficient of thermal expansion that is similar to the tooth structure, thus facilitating mineralization of the affected structure. When the cavity preparation is conservative and the cavity margins are on hypomineralized enamel, bonding with totaletch adhesive is poor, as described by William et al. [27].

In the present study, the mean of age of the children was 7 years and FPMs were severely affected. Considering the tooth maintenance on the mouth as long as possible, the conservative approach, as varnish fluoride application and provisional GIC restoration, was performed for all of the affected FPMs, as proposed in previous studies [35]. This approach is fundamental once GIC favors remineralization of the affected enamel, protects it from carious lesions, and promotes desensitization
[11] and hygiene, which is important for resin composite maintained. Moreover, the GIC restorations were performed to avoid poor bonding of adhesive materials with the affected enamel. However, GIC is not recommended in stress-bearing areas, such as occlusal surfaces of hypomineralized molars, but it was effective until a definitive restoration is placed.

Several adhesives are available for bonding composite resin to enamel [29]. Among these, total-etch three-step adhesive and two-step self-etching primer adhesive have shown consistent and successful bonding to ground enamel. Self-etching adhesives promote hybridization with incorporation of the smear layer on the hydride layer without acid etching as a separate step in the adhesive protocol. These adhesives have shown satisfactory results [29, 30]. They were designed to avoid extensive areas of dissolution and to not impregnate the area with resin monomers, thus eliminating the critical step of the adhesive system and facilitating restoration, thereby decreasing the chances of adhesion failure [29]. These properties can be beneficial to the hypomineralized dental surfaces because with no etching, the extent of demineralization is the lowest and postoperative sensitivity is reduced. William et al. [27] compared in vitro the microshear bond strength and failure modes of total-etch single-bond adhesive (Single Bond, 3M ESPE) and a self-etching adhesive (Clearfil SE Bond, Kuraray Medical) in hypomineralized and control enamel specimens in vitro. The authors found that the microshear bond strength in hypomineralized enamel was significantly lower than the control enamel. With regard to the adhesives used, the self-etching adhesive presented significantly higher microshear bond strength 
than the total-etch adhesive. These authors attributed their results to inadequate microtag formation in the all-etch adhesive.

With regard to the clinical evaluations, failures were attributable to marginal adaptation, retention, and secondary carious lesions. These findings corroborate William et al. [27], who reported a high frequency of cohesive failures in hypomineralized enamel specimens that presented a weakened structure. Future clinical trial should be done evaluating the clinical survival of composite resin and GIC restorations in a sound enamel and hypomineralized enamel (conservative cavity margins). Once, some authors recommend pretreating the enamel with $5 \%$ sodium hypochlorite to de-proteinate the hydroxyapatite, while others authors recommend removing all defective hypomineralized enamel prior to bonding resin composite [18].

\section{Conclusion}

Within the limitations of the present clinical trial, according to our data, it can be concluded that when the cavity preparation is conservative, it can be suggested that self-etching adhesives can be applied, as well as total-etch adhesive in restorations of molars that are affected by $\mathrm{MIH}$, permitting good clinical success rates. Once, cavosurface margins (cavity design) in hypomineralized enamel have less bonding capability, and restorations that use modern adhesives may be a reasonable choice for molars that are affected by MIH.

Acknowledgments This study was supported by the Brazilian Coordination of Superior Education, Ministry of Education (CAPES) and FAPESP (2011/17528-2).

\section{Compliance with ethical standards}

Conflict of interest The authors declare that they have no conflict of interest.

Funding The study was supported by the Brazilian Coordination of Superior Education, Ministry of Education (CAPES) and FAPESP (2011/17528-2).

Ethical approval All procedures performed in the study involving human participants were in accordance with the ethical standards of the institution and with the 1964 Helsinki Declaration and its later amendments or comparable ethical standards.

Informed consent Informed consent was obtained from all individual participants included in the study.

\section{References}

1. Weerheijm KL (2004) Molar incisor hypomineralization (MIH): clinical presentation, aetiology and management. Dent Update 31:9-12
2. Weerheijm KL, Jalevik B, Alaluusua S (2001) Molar-incisor hypomineralisation. Caries Res 35:390-391

3. Alaluusua $S$ (2010) Aetiology of molar-incisor hypomineralisation: a systematic review. Eur Arch Paediatr Dent 11:53-58

4. Souza JF, Costa-Silva CM, Jeremias F, Santos-Pinto L, Zuanon AC, Cordeiro RC (2012) Molar incisor hypomineralisation: possible aetiological factors in children from urban and rural areas. Eur Arch Paediatr Dent 13:164-170

5. Souza JF, Jeremias F, Costa-Silva CM, Santos-Pinto L, Zuanon AC, Cordeiro RC (2013) Aetiology of molar-incisor hypomineralisation $(\mathrm{MIH})$ in Brazilian children. Eur Arch Paediatr Dent 14:233-238

6. Serna C, Vicente A, Finke C, Ortiz AJ (2016) Drugs related to the etiology of molar incisor hypomineralization: a systematic review. J Am Dent Assoc 147:120-130

7. Jeremias F, Koruyucu M, Kuchler EC, Bayram M, Tuna EB, Deeley K, Pierri RA, Souza JF, Fragelli CM, Paschoal MA, Gencay K, Seymen F, Caminaga RM, Dos Santos-Pinto L, Vieira AR (2013) Genes expressed in dental enamel development are associated with molar-incisor hypomineralization. Arch Oral Biol 58:1434-1442

8. Bullio Fragelli CM, Jeremias F, Feltrin de Souza J, Paschoal MA, de Cassia Loiola Cordeiro R, Santos-Pinto L (2015) Longitudinal evaluation of the structural integrity of teeth affected by molar incisor hypomineralisation. Caries Res 49:378-383

9. Jalevik B. (2001) Enamel hypomineralization in permanent first molars. A clinical, histo-morphological and biochemical study. Swed Dent J Suppl:1-86.

10. Da Costa-Silva CM, Ambrosano GM, Jeremias F, De Souza JF, Mialhe FL (2011) Increase in severity of molar-incisor hypomineralization and its relationship with the colour of enamel opacity: a prospective cohort study. Int J Paediatr Dent 21:333-341

11. Fragelli CM, Souza JF, Jeremias F, Cordeiro Rde C, Santos-Pinto L (2015) Molar incisor hypomineralization (MIH): conservative treatment management to restore affected teeth. Braz Oral Res 29:1-7

12. Jeremias F, de Souza JF, Silva CM, Cordeiro Rde C, Zuanon AC, Santos-Pinto L (2013) Dental caries experience and molar-incisor hypomineralization. Acta Odontol Scand 71:870-876

13. Lygidakis NA, Wong F, Jalevik B, Vierrou AM, Alaluusua S, Espelid I (2010) Best clinical practice guidance for clinicians dealing with children presenting with molar-incisor-hypomineralisation (MIH): an EAPD policy document. Eur Arch Paediatr Dent 11: $75-81$

14. da Costa-Silva CM, Jeremias F, de Souza JF, Cordeiro Rde C, Santos-Pinto L, Zuanon AC (2010) Molar incisor hypomineralization: prevalence, severity and clinical consequences in Brazilian children. Int J Paediatr Dent 20:426-434

15. Elfrink ME, Ghanim A, Manton DJ, Weerheijm KL (2015) Standardised studies on molar incisor hypomineralisation (MIH) and hypomineralised second primary molars (HSPM): a need. Eur Arch Paediatr Dent 16:247-255

16. Wulaerhan J, Abudureyimu A, Bao XL, Zhao J (2014) Risk determinants associated with early childhood caries in Uygur children: a preschool-based cross-sectional study. BMC Oral Health 14:136

17. Lygidakis NA, Chaliasou A, Siounas G (2003) Evaluation of composite restorations in hypomineralised permanent molars: a four year clinical study. Eur J Paediatr Dent 4:143-148

18. Mathu-Maju K, Wright JT (2006) Diagnosis and treatment of molar incisor hypomineralization. Compend Contin Educ Dent 27: 606-610

19. Mejare I, Bergman E, Grindefjord M (2005) Hypomineralized molars and incisors of unknown origin: treatment outcome at age 18 years. Int J Paediatr Dent 15:20-28

20. Kotsanos N, Kaklamanos EG, Arapostathis K (2005) Treatment management of first permanent molars in children with molarincisor hypomineralisation. Eur J Paediatr Dent 6:179-184 
21. Jalevik B, Klingberg GA (2002) Dental treatment, dental fear and behaviour management problems in children with severe enamel hypomineralization of their permanent first molars. Int J Paediatr Dent 12:24-32

22. Fearne J, Anderson P, Davis GR (2004) 3D X-ray microscopic study of the extent of variations in enamel density in first permanent molars with idiopathic enamel hypomineralisation. Br Dent J 196: 634-638 discussion 625

23. Jalevik B, Dietz W, Noren JG (2005) Scanning electron micrograph analysis of hypomineralized enamel in permanent first molars. Int $\mathrm{J}$ Paediatr Dent 15:233-240

24. Mahoney E, Ismail FS, Kilpatrick N, Swain M (2004) Mechanical properties across hypomineralized/hypoplastic enamel of first permanent molar teeth. Eur J Oral Sci 112:497-502

25. Fagrell TG, Dietz W, Jalevik B, Noren JG (2010) Chemical, mechanical and morphological properties of hypomineralized enamel of permanent first molars. Acta Odontol Scand 68:215-222

26. Farah RA, Swain MV, Drummond BK, Cook R, Atieh M (2010) Mineral density of hypomineralised enamel. J Dent 38:50-58

27. William V, Burrow MF, Palamara JE, Messer LB (2006) Microshear bond strength of resin composite to teeth affected by molar hypomineralization using 2 adhesive systems. Pediatr Dent 28:233-241

28. William V, Messer LB, Burrow MF (2006) Molar incisor hypomineralization: review and recommendations for clinical management. Pediatr Dent 28:224-232
29. De Munck J, Van Landuyt K, Peumans M, Poitevin A, Lambrechts P, Braem M, Van Meerbeek B (2005) A critical review of the durability of adhesion to tooth tissue: methods and results. J Dent Res 84:118-132

30. Furuse AY, Cunha LF, Moresca R, Paganeli G, Mondelli RF, Mondelli J (2011) Enamel wetness effects on bond strength using different adhesive systems. Oper Dent 36:274-280

31. Weerheijm KL, Duggal M, Mejare I, Papagiannoulis L, Koch G, Martens LC, Hallonsten AL (2003) Judgement criteria for molar incisor hypomineralisation (MIH) in epidemiologic studies: a summary of the European meeting on MIH held in Athens, 2003. Eur J Paediatr Dent 4:110-113

32. Organization WH (1997) Oral health surveys: basic methods, 4th edn. WHO, Genebra

33. Cvar JF, Ryge G (2005) Reprint of criteria for the clinical evaluation of dental restorative materials. 1971. Clin Oral Investig 9:215-232

34. Casagrande L, Seminario AT, Correa MB, Werle SB, Maltz M, Demarco FF, Araujo FB (2016) Longevity and associated risk factors in adhesive restorations of young permanent teeth after complete and selective caries removal: a retrospective study. Clin Oral Investig. doi:10.1007/s00784-016-1832-1

35. Qiu RM, Lo EC, Zhi QH, Zhou Y, Tao Y, Lin HC (2014) Factors related to children's caries: a structural equation modeling approach. BMC Public Health 14:1071 